\title{
Imagem no Judaísmo: Aspectos do “Aniconismo” Identitário
}

\author{
Ivan Esperança Rocha*
}

Resumo: As fontes visuais ganham um espaço cada vez mais amplo entre as ciências humanas e sociais. Na historiografia considera-se sua capacidade de representar os imaginários sociais e de evidenciar as mentalidades coletivas, enriquecendo ou preenchendo vazios deixados pela documentação escrita. Na cultura judaica, no entanto, a imagem teve um tratamento muito particular, tornando-se um elemento distintivo de sua identidade. O que inicialmente tinha como intenção garantir o monoteísmo javístico acaba por definir um certo aniconismo que só muito recentemente foi superado.

Palavras-Chave: Judaísmo, Monoteísmo, Haskalah.

A imagem tem recebido uma crescente atenção no âmbito das ciências sociais e humanas, particularmente no campo da historiografia, o que se depreende de inúmeros eventos e publicações nivelem âmbito nacional e internacional. As imagens, ou fontes visuais, começam a ser tratadas como uma importante evidência histórica, e igualadas em valor à literatura e documentos de arquivos. ${ }^{1}$ Em vez de seu valor afetivo e subjetivo que tinha caracterizado a Antiguidade e a Idade Média, buscam-se agora conhecimentos mais sistemáticos e consistentes sobre elas. Demonstra-se que os fatos sociais se refletem em mecanismos visuais. ${ }^{2}$

A cerâmica, manuscritos com pinturas, imagens soltas de propaganda política e religiosa, quadros, estátuas, fotografias ou simplesmente material visual ganham uma importância não mais apenas ligada às suas qualidades estéticas mas à sua capacidade de representar os imaginários sociais e de evidenciar as mentalidades coletivas. "No estudo das sociedades antigas, a iconografia, neste seu significado mais amplo de material visual, assume um papel de destaque, particularmente, quando não se tem a contrapartida da documentação escrita ou quando esta é lacônica", como se verifica na iconografia funerária ou templária do Egito. ${ }^{4}$

Por outro lado, na cultura judaica, bem próxima do Egito, no espaço e no tempo, o acesso a dados provenientes da iconografia é muito limitado. ${ }^{5}$

Os judeus consideraram sua religião e seu código religioso de comportamento um elemento essencial de sua identidade e de sua sobrevivência ante os inúmeros momentos de dispersão em que foi envolvido. Entre as leis do corpo normativo israelita 
se encontra uma proibição de produzir ou conservar imagens com o intuito de preservar uma idéia de monoteísmo, que iria de certa forma represar a arte israelita durante séculos. A proibição, inicialmente ligada à reprodução de ídolos estrangeiros, acaba se estendendo a outros tipos de representação iconográfica, particularmente ligada à figura humana - considera-se o homem criado à imagem de Deus, que vigorou, com uma certa intensidade, praticamente até as portas da Haskalah, o iluminismo judaico, iniciado em fins do século XVIII.

A normalização da proibição de imagens em Israel encontra-se no livro do Êxodo: "Não farás para ti imagem de escultura, nem semelhança alguma do que há em cima, nos céus, nem embaixo, na terra, nem nas águas debaixo da terra" (20,4). Esta proibição faz parte da legislação religiosa de Moisés e pode ser entendida, dentre outros textos, por meio de Isaías: “A quem havereis de comparar a Deus? Que semelhança podereis produzir dele?" $(40,18)$.

Em um ambiente permeado por cultos idolátricos (Ex 20,5; 34,15, Sl 44,21, 1 Rs 11,8ss, 19,18, Jr 7,18, Is 10,10), os judeus querem se distinguir pela ausência de imagens de Javé. Assim, com raras exceções, com veremos mais adiante, fica proibida a produção de efígies da divindade israelita. ${ }^{6}$ Isso, no entanto, não vai banir a presença de imagens. Uma das estratégias nesse sentido será a utilizada por Salomão que passa a contratar artistas externos à comunidade israelita para a construção e embelezamento do Templo de Jerusalém, como é o caso de Hiram, um artista de Tiro que tinha grande habilidade no trabalho com bronze (1 Rs 7,13-14). Entende-se, assim, que a proibição não atingia os artistas estrangeiros e dessa maneira se pode justificar a presença de figuras de querubins e leões nos painéis do Templo (1 Rs 7,26).

Uma outra razão da presença de imagens entre os judeus envolvia o casamento dos reis israelitas com estrangeiras que traziam consigo seus cultos e seus deuses. ${ }^{7}$ De fato, as descobertas arqueológicas trouxeram à tona uma série de iconografias do período bíblico, como sinetes com figuras de animais, plantas e outros objetos e figuras em argila de nus femininos, estas muito comuns em Jerusalém.

Sinagogas do período próximo à destruição do Templo, em 70 d.C., possuem decorações com figuras geométricas e de plantas; entre os judeus que participaram da revolta de Bar-Kokhba contra os romanos, em 135 d.C., foram encontrados vasos decorados com faces humanas; mas para que se evitasse seu uso como objetos idolátricos os olhos foram apagados. ${ }^{8}$ 
No entanto, mesmo com relação à proibição da representação de Javé, existem exceções, como se verifica numa fortaleza, em Kuntillet 'Ajrud, na Península do Sinai, onde foram encontrados graffiti com imagens de Iahweh ao lado de sua Ashera. ${ }^{9}$

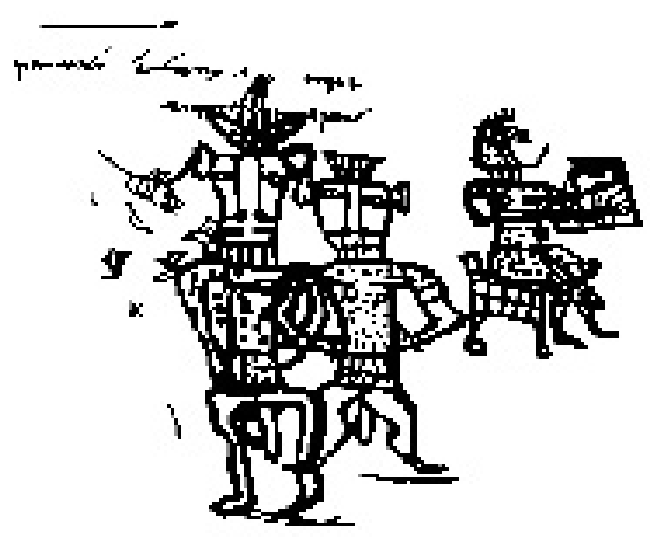

Grafitti de Kuntillet Ajrud, sul do Negev, séc. VIII a.C. Encontrado em fragmento de cerâmica, com figura de Javé, à esquerda, e sua consorte Asherah, à direita.

Pode-se dizer que os judeus foram mais tolerantes com imagens que não tivessem relações com o culto. Com o declínio do politeísmo helênico-romano, muitas sinagogas começam a usar motivos da iconografia pagã, adaptando-as às suas necessidades, assim como cenas bíblicas como as da sinagoga de Dura-Europos nas proximidades do rio Eufrates. ${ }^{10}$

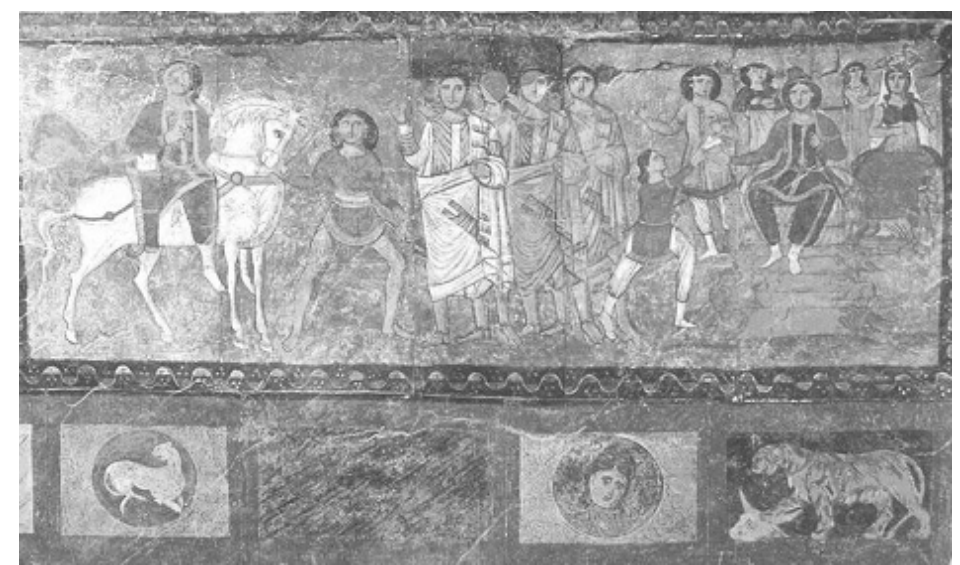

Cenas do livro de Ester na Sinagoga de Dura Europos, Mesopâtamia, Parthia. Museu de Damasco 
No século VII, com a conquista do Oriente pelo Islamismo anicônico, os judeus voltam a abandonar as imagens, adaptando-se à nova situação. As constantes dificuldades postas pelo segundo mandamento podem ser vislumbradas no manuscrito judaico ilustrado, chamado Haggadah da Cabeça de Ave. O texto narra a história do êxodo do Egito, onde todas as figuras humanas são representadas por cabeças de pássaros para evitar a proibição icônica.

A discussão sobre a questão da imagem do Antigo Testamento é retomada no Talmude, uma compilação e adaptação de leis e tradições judaicas, realizadas entre 200 a.C. e 500 d.C., que consistem em 63 tratados de assuntos legais, éticos e históricos. O judaísmo ortodoxo baseia suas leis no texto do Talmude. Tem entre seus tratados um específico sobre imagens e ídolos, o 'Abodah Zarah.

De um lado, este tratado expressa uma rígida oposição aos ídolos, proibindo não apenas sua fabricação, mas até mesmo olhar e pensar neles (Tosefta, Shabbath 17,1 et passim; Berakhot 12b). Os ídolos não deviam ser apenas quebrados, mas jogados no Mar Morto para que não pudessem ser mais vistos ('Abodah Zarah 3,3). A madeira de uma asherah não podia ser usada nem para aquecer-se (Pesahim, 25a). Para evitar qualquer contato com os idólatras, os judeus não podiam relacionar-se comercialmente com eles pelo menos três dias antes de suas festas cultuais ('Abodah Zarah 1,1). Ficava proibido caminhar sobre uma rua pavimentada com pedras que tinham sido utilizadas para construir o pedestal de um ídolo ('Abodah Zarah 50a). Aos sábados era proibido até mesmo ler o que estava escrito sob uma pintura ou estátua ('Abodah Zarah 149).

Por outro lado, encontramos no Talmude posições mais abertas com relação às imagens. Não se proíbe qualquer imagem, mas apenas aquelas que tenham um cunho cultual. Estátuas de reis, em um ambiente em que não são consideradas objeto de culto, não são proibidas ('Abodah Zarah 40a). Imagens para ornamentação são permitidas. Qualquer figura dos planetas é permitida, com exceção do sol e da lua (quase sempre representados com cunho cultual) ('Abodah Zarah 43b). Uma asherah é uma árvore sob a qual se pratica um culto e, portanto, proibida. Se, no entanto, existir um altar de pedras sob ela, a árvore pode ser utilizada livremente ('Abodah Zarah 48a).

A ambigüidade do tratamento dado às imagens começa a declinar com a Haskalah, um movimento entre judeus europeus do séc. XVIII, conhecido como o iluminismo judaico, calcado nos valores iluministas, que buscou promover maior 
integração com a sociedade européia, ampliando o espaço da educação secular e definindo os rumos de um movimento político pela emancipação judaica. ${ }^{11}$

O movimento encontrou inicialmente oposição entre os judeus ortodoxos por julgarem que a Haskalah contrariava os princípios do judaísmo tradicional, mas não deixou de ter adeptos entre eles. Uma das idéias contrapostas pela Haskalah é a do messianismo, como a espera de um gesto miraculoso em favor dos judeus; o exílio judaico também deixa de ser interpretado como uma vontade divina, mas como resultado de fatores históricos. ${ }^{12}$ Outra influência foi nas artes, com uma ampla revisão de proibições tradicionais, particularmente no que se refere à proibição de imagens.

Como reflexo desse movimento, nos séculos XIX e XX vimos o surgimento de grandes artistas judeus como Marc Chagall (1887-1985) com seus esplêndidos vitrais das doze tribos judaicas conservados na Sinagoga do Hospital Hadassa de Jerusalém, e Lasar Segall, um judeu lituano radicado no Brasil que transformou sua casa em museu com um acervo em torno de 2.500 obras.

Deve-se dizer, no entanto, que a Haskalah, do ponto de vista artístico, foi precedida pela ação de judeus, que apesar de não se envolverem com a pintura já tinham se dedicado a outros tipos de expressões artísticas, como a joalheria, cunhagem de moedas e medalhas, ourivesaria, gravação em madeira, cerâmica, caligrafia e ilustração de manuscritos hebraicos, dentre outras. ${ }^{13}$

Numa exposição realizada no Museu Judaico de Nova York, de 18 de novembro de 2001 a 17 de março de 2003, foi apresentada e discutida a arte desenvolvida durante o processo de aculturação judaica no século XIX, sendo apresentada como uma das conseqüências da Haskalah.

Por fim, os judeus, ao se perguntarem se suas antigas leis ainda têm algum valor na atualidade, particularmente, se a proibição de imagens como objeto de culto ainda tem algum valor para a sociedade moderna, encontram uma resposta nas palavras de uma exegeta judia, Nechama Leibowitz (1905-1997), para quem o segundo mandamento ainda continua válido, dado que objetos e bens de materiais, ou a própria ciência, são guindados a uma posição de culto no mundo moderno. ${ }^{14}$

ROCHA, Ivan Esperança. Image in Judaism: Aspects of Indentity "Aniconism". História, São Paulo, v. 26, n. 1, p 119-124, 2007.

Abstract: The visual sources acquire a wider space among the humanities. In the historiography its capacity to represent the social imaginary and to evidence the 
collective mentalities have been considered, enriching or filling out spaces left by the written documentation. In the Jewish culture, however, the image had a very special treatment, becoming a distinctive element of its identity. What initially had as intention to guarantee the javistic monotheism ended for defining a certain aniconism that only very recently was overcome.

Keywords: Judaism, Monotheism, Haskalah

Artigo recebido em 03/2007. Aprovado em 05/2007.

\section{NOTAS}

\footnotetext{
* Professor de História Antiga do departamento de História - Faculdade de Ciências e Letras de Assis Unesp - 19806-900 - Assis/SP. E-mail: ierocha@uol.com.br

${ }^{1}$ BURKE, Peter. O testemunho das imagens. In: Testemunho ocular. História e imagem. Bauru: Edusc, 2004. p.15.

${ }^{2}$ MENESES, Ulpiano T. Bezerra de. Fontes visuais, cultura visual, História visual. Balanço provisório, propostas cautelares. Revista Brasileira História, v.23, n.45, 2003, p. 11 ss.

${ }^{3}$ CHARTIER, R. Imagens. In: BURGUIÈRE, A. Dicionário das Ciências Históricas. Trad. Jayme Salomão. Rio de Janeiro: Imago, 1993. p.406-7.

${ }^{4}$ ROCHA, Ivan Esperança. Práticas e representações judaico-cristãs. Assis: FCL - Assis - Unesp Publicações, 2004. p.29.

${ }^{5}$ LIVERANI, Mario. Antico Oriente. Storia, Società, Economia. Bari: Laterza, 2005. p.688-689.

${ }^{6}$ VON RAD, G. Eikôn. In: KITTEL, G. (ed.). Grande Lessico del Nuovo Testamento. Brescia: Paideia, 1967.v.3,col. 143.

${ }^{7}$ EHRLICH, Car. Make yourself no graven image: The Second Commandment and Judaism. In: et
} al. Thirty Years of Judaic Studies at the University of Massachusetts Amherst. Massachusetts: University of Massachusetts Amherst, 2004. p.254-271.

${ }^{8}$ YADIN, Yigael Yadin. Bar-Kokhba: The Rediscovery of the Legendary Hero of the Last Jewish Revolt against Imperial Rome (London: Weidenfeld and Nicolson, 1971), p. 86-111, apud EHRLICH, Car. Make yourself no graven image: The Second Commandment and Judaism. In: et al. Thirty

Years of Judaic Studies at the University of Massachusetts Amherst. Massachusetts: University of Massachusetts Amherst, 2004. p.261.

${ }^{9}$ DEVER, William G. Asherah, consort of Yahweh? New evidence from Kuntillet Ajrud. Bulletin of the American Schools of Oriental Research, n. 255, 1984, p.21ss.

${ }^{10}$ KRAELING, Carl H. The Synagogue. (The Excavations at Dura-Europos Final Report 8/1. New Haven: Yale University, 1956). Citado por EHRLICH, Car. Make yourself no graven image: The Second Commandment and Judaism. In: et al. Thirty Years of Judaic Studies at the University of Massachusetts Amherst. Massachusetts: University of Massachusetts Amherst, 2004. p.262ss.

11 ROSENTHAL, Herman Peter. Haskalah. In: WIERNIK, Singer, Isidore; Alder, Cyrus (eds.) et al (1901-1906). The Jewish Encyclopedia. New York: Funk and Wagnalls, v.8, 1901-1906, p.256-258.

12 SHOENBERG, Shira. The haskalah. Disponível em: http://www.jewishvirtuallibrary.org. Acesso em 10 de setembro de 2006.

13 PASTERNAK, Velvel. Music and art. Disponível em: http://www.judaism.com/12paths/music\&art.htm. Acesso em 06 de setembro de 2006.

14 GROSSBARD, Sylvie. $\quad$ Shemot-Yitro. http://www.usy.org/yourusy/reled/dt/readdvar.asp?dvar=161. Acesso em 03 nov. 2006. 